\title{
A Novel Collaboration Management Method Based Finance Logistics Management Platform
}

\author{
Zhongdai $\mathrm{Wu}^{1}$, Minghai $\mathrm{Ye}^{1}$ and Jin $\mathrm{Liu}^{2,3}$ \\ ${ }^{1}$ School of Economics and Management, Tongji University, Shanghai, China \\ Key Laboratory of Embedded System and Service Computing Ministry of Education, \\ Tongji University, Shanghai, China \\ ${ }^{3}$ College of Info. Engineering, Shanghai Maritime University, Shanghai, China \\ \{wzd,mhy,\}@cnshipping.com; jinliu@shmtu.edu.cn

\section{Abstract} \\ In order to solve current realistic problems such as low-efficiency in resource allocation, \\ difficulty in headquarters integrated management, high-risk infinance, and inaccuracy and \\ untimeliness of information sharing. On the basis of collaborative management theory and \\ information technology, centralized standardization of information system of finance logistics \\ as a management platform is constructed in the study. Standardization of business processes \\ and uniform control of headquarter are initiolly realized, the needs of business operations as \\ well as logistics management are effectively met, and using information technology to \\ promote the meticulous management is achieked. Information management of finance \\ logistics reduces the financial risk strengthen the management of supervisors, and promote \\ the capabilities of project management.
}

Keywords: finance logisttcs; collabokative management; information system

\section{Introduction}

As a new ervice model, finance logistics transforms the concept of "combination of logistics, capitalfow and ifformation flow" into reality, thus, to some extent, solving the financial problems in the supply chain, despite remaining some problems. At present, some problems, including poor supply chain system management, low finance logistics service efficiency, high financial risk, uneasily guaranteed timeliness and accuracy of information sharing, hinder the further development of finance logistics business. This writer believes that by combining the integration and coordination of the supply chain, the collaboration management method largely solves the above problems, reduces risks, strengthens control, thereby ensuring the good operation of a supply chain. Financial service is indispensable to the development of modern logistics. Finance logistics resulting from combination of financial service and logistics service can not only enhance the service ability and operating profits of the third-party logistics enterprises, but also can assist enterprises in expanding financing channels, lowering financing costs, raising capital utilization, and improving their integrated services. Meanwhile, it can provide new ideas and methods for the business innovation and profit increases of financial institutions.

The building of finance logistics management information platform in this document is an effective tool to improve business management. Integrating such functions as inventory pledge, financial pledge and risk management, this platform focusing on financial pledge delivers the seamless connection of modules, combines the physical inventory supervision, workload statistics and cost accounting, and provides a basis for all-round management decision-making of inventory pledge parties. It can ensure the effective integration of 
logistics, capital flow and information flow, provide the third-party logistics enterprises, supply chain enterprises and financial institutions with timely and efficient information-based services [1], effectively prevent financial risks such as pledge by warehouse receipts, settlement and finance services, improve business operation efficiency, reduce management and logistics costs in order to enable logistics regulators, banks, producers, and dealers, etc. to gain profits, and finally enhance the industrial chain level.

\section{Finance Logistics}

\subsection{Concept of Finance Logistics}

Finance logistics, that is, organic combination of finance service and logistics service, mainly means that the third-party logistics enterprises provide a new business combining finance service and logistics service in the supply chain. It mainly includes: logistics, distribution processing, financing, evaluation supervision asset disposal, and financial consultation, etc., [2].

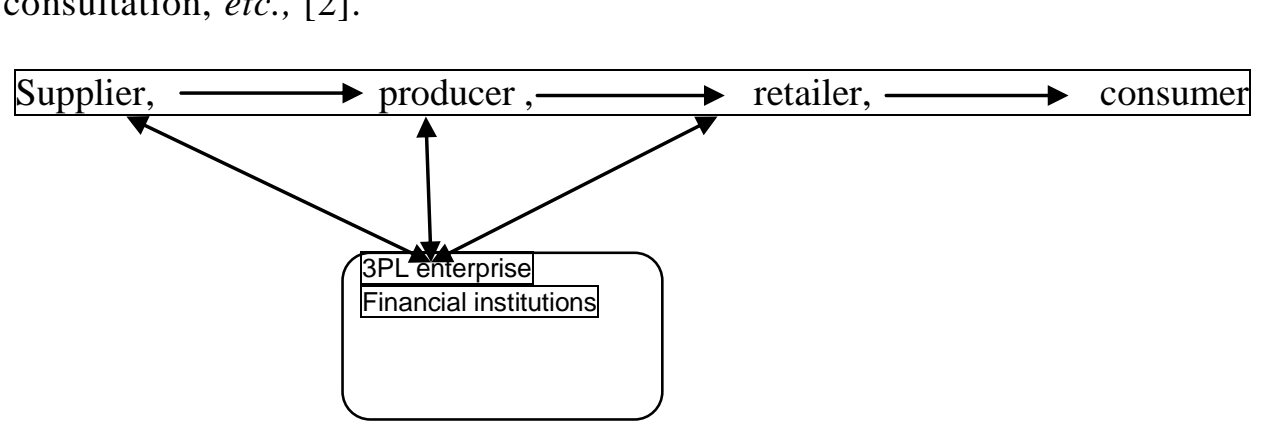

\section{Figure 1. Finance Logistics System}

Figure 1 shows that the organic combination of the third-party logistics enterprises and financial institutions provides logistics and finance integrated services to the suppliers, producers, retailers, and consumers in the supply chain, thus delivering the financial service innovation of traditional logistics and value increase of the supply chain.

There are many foreign literature and plentiful results on the improvement of management level and risk control. Buzacott and Zhang [3] conducted the quantitative research on the determination of some important indexes in business (e.g., interest rates and loan limit and their impact on business risks. Barsky and Catanach [4] believe that business financing related to finance logistics is different from traditional loan on credit, and that practice business control should be transformed into process control from basic risk control of subject access. Diercks [5] holds that finance logistics business must be strictly monitored. He introduces some specific monitoring methods for effective monitoring and management improvement, and describes the necessity of requiring the third parties or logistics enterprises to participate in monitoring. Comparatively speaking, there is less research on the above respects in China, and few existing models are available with low risk control level. This should receive more attention [6].

\subsection{Business Models of Finance Logistics}

At present, China's business models of finance logistics mainly fall into two categories: one category is inventory-based finance logistics model, including the 
pledge by warehouse receipts and inventory pledge business models; the other category is trade contract based business model of finance logistics, including the accounts receivable financing and order financing [7].

The main models of China Shipping Logistics Co.,Ltd. described in this document include the pledge by warehouse receipts, commodity finance cabin, full process business, and future cargo right).

Pledge by warehouse receipts: With warehouse receipt as a subject matter, the cargo owner enterprise stores its pledged goods in the warehouse of the logistics enterprise, and applies to the bank for loan by means of a warehouse receipt (list of pledged goods). According to the value of pledged goods and other related factors, the bank will offer a certain proportion of line of credit.

Full process business: The logistics company conducts the full-process monitoring and supervision on the whole transport and storage of pledged goods, thus delivering the full-process and seamless dynamic supervision.

Commodity finance cabin: It refers to a full-process pledge supervision model that is based on the supervision of the goods in transit by sea and contains the supervision of the goods at the warehouses (storage yard) of both parties in line with the traditional marine transport business of China Shipping Logistics Co, Ltd. and the concept of pledge by warehouse receipt.

Future cargo right: It refers to the business model in which pledged goods are warehoused in batches, and finally detivered from the warehouse uniformly according to the ex-warehouse instructions of the bank.

\subsection{Supervision Models of Finance Logistics}

Local supervision: A legistics company uses its self-owned/self-run warehouses nationwide to store pledged goods of financing enterprises. This model applies to the business of pledge by warehouse rêceipts and future cargo right.

Output supervision: A logistics company directly sends professional supervision personnel to the warehouse or site of the supervision enterprise to supervise the products pledged to the bank on the scene. This model applies to the business of pledge by warehouse receipts and future cargo right. This is the currently main supervision model of China Shipping Logistics Co.,Ltd. in the finance logistics business.

In-transit superoision: A logistics company directly participates in the procurement or sales and transport of goods of financing customers, extends the supervision scope to the place of receipt/delivery and brings the goods transport link into the supervision scope. Thi model applies to the full process business and commodity finance cabin business.

Comprehensive supervision: A logistics company conducts the full-process monitoring and supervision on the whole transport and warehousing of pledged goods, thus delivering the full-process seamless dynamic supervision. This model applies to the full process business and commodity finance cabin business.

\subsection{Financial Risks of Finance Logistics}

Generally, finance logistics risks include internal management risk, operation risk, technical risk, market risk, safety risk, environmental risk, law risk, and credit risk, etc.

This document focuses on the financial risks in the finance logistics, including: 


\section{Pledge by Warehouse Receipt Service Risk}

Pledge by warehouse receipt service risk mainly originates in the pledged goods. The quality of pledged goods will largely influence the attainment of loan principal and profits from the bank, and asymmetric product information makes the pledge loan business possibly face a great risk. The main risk originates in the following: The price of pledged goods usually fluctuates with time, and as the product price continuously runs low, the guarantee extent of pledge loan will fall; pledged goods with unidentified sources may be smuggled products or may has confiscation risk; pledged goods may have quality that does not comply with the requirement of the pledge loan agreement. In addition, the uniqueness of warehouse receipt will not be effectively guaranteed, leading to a forging risk.

\section{Settlement Service Risk}

The logistics settlement service mainly means that a finane logistics service enterprise provides financial settlement service to logistics enterprise and its customers using various settlement modes, including the colledtion on delivery, payment in advance, and acceptance bill, etc. The high-speed operation property of the logistics industry leads to the fact that the risk confronted by finance logistics is enlarged due to a leverage effect. Compared w/th traditional static settlement service, the product form of logistics settlement service is atways changing, bringing about extra control risk. Additionally, finance logistics settlement business involves lots of financial innovation and electronic network settement. This raises higher requirements for security technology of finandiakenterprises.

\section{Financing Service Risk}

Financing repayment is based on the valid enterprise capital flow and the authentic transactions, and bogus transactions divectly affect capital collection. China is short of perfect credit rating information, which increases financing risk and supervision costs of bogus transactions. Financing involves multiple participants. But it is short of risk sharing and mutually bepeficial income mechanism of participants, causing each participant to unilateralty transfer risk and meeting the financing risk of "adverse selection". The traditional financing risk rating system is hard to adapt to operating condition of finance logistics. Moreover, the mechanism defects bring about extra financing service risk.

\section{Logistics Enterprise Risk}

An imperfect finance system and poorly transparent enterprise information cause a logisties enterprise to have low credit standing. With a shortage of property that can be used os guaranteed mortgage, small- and medium-sized logistics enterprises usually have a high asset-liability ratio, and most of property has been mortgaged. Therefore, pledged goods for new loan application are seriously insufficient. Furthermore, as some logistics enterprises and operators with low management and quality meet difficult operation, they will do everything possible to default on their loan interest. As a result, they not only pose a great threat to loan fund safety of financial institutions, but also largely lower their creditworthiness and increase the difficulty of logistics enterprises in getting new loans [8]. 


\section{Construction of Finance Logistics Management Platform Based on Collaboration Management}

Coordination management is indispensable to combination of finance with logistics to form a unified finance logistics management platform to serve enterprises. Coordination management means correlating various resources of an enterprise including human resources, customers, properties, information, and processes) so that they are coordinated to achieve common tasks or goals. Limited resources are used to the maximum extent to achieve their benefit maximization and eliminate various obstacles and barriers generated in the coordination process. The system based on coordination management comprises four elements: people, information, procedure, and application, wherein the synergy of people is the core, while the synergy of information, procedure and application all serve the,efficient synergy of people [9]. The finance logistics management platform dealt with in thils document covers the transport, production, marketing and managêment of/traditional logistics enterprises, pledge by warehouse receipts, commodity finance cabin, ful process business, and future cargo right. It can satisfy not only daily business operation requirements, but also statistical analysis, business settlement and decision management requirements (see Figure 2 for platform construction). This, to a large extent, improves the efficiency of logistics enterprises, reduces financial risks and delivers fuformation sharing.

\subsection{Modeling of Finance Logistics Management Platform Based on Collaboration Management}

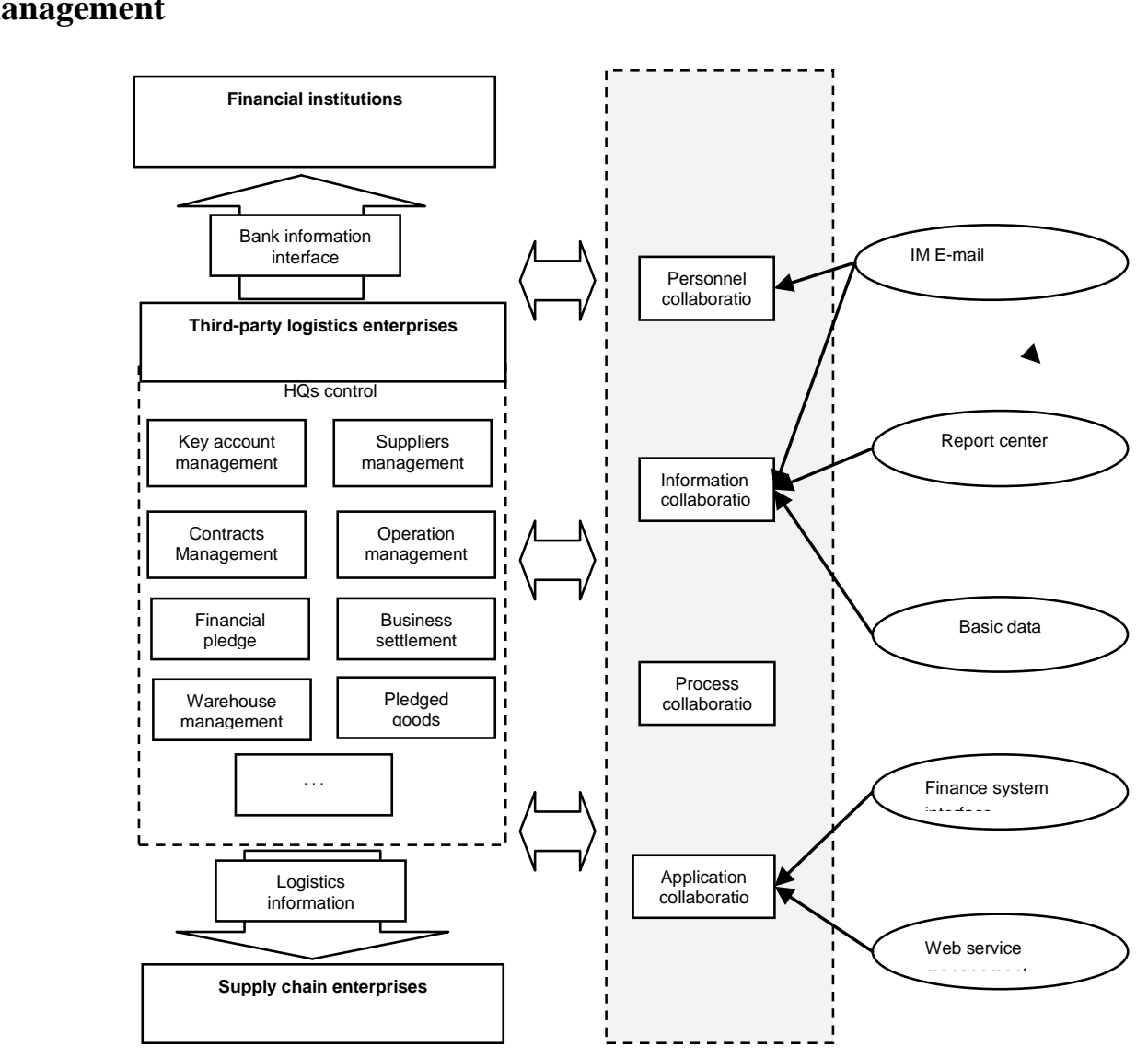

Figure 2. Model of Finance Logistics Management Platform 
The finance logistics management platform based on collaboration management is mainly embodied in the information collaboration and various data collaboration and sharing of financial institutions, third-party logistics enterprises and supply chain enterprises. The four finance logistics business models, i.e., the pledge by warehouse receipts, commodity finance cabin, full process business, and future cargo right, basically deliver the collaboration in terms of personnel, information, process and application.

(1) Information collaboration of financial service institutions, logistics enterprises and supply chain enterprises: Through bank information interface and logistics information interface, logistics enterprises can connect financial service institutions and supply chain enterprises. Thus, enterprises can continuously grasp the supply chain logistics information and logistics enterprise can communicate the finance and fund information involyed in business with the banks. The construction of such information system platforp is able to deliver information sharing and reduce financial risks, to a great extent. Inside the logistics enterprises, the HQs control and classified modules should ${ }^{\bullet}$ also Aeliver collaboration management, and the HQs supervise and manage the operation process of each module from a strategic management perspective, and enjoy the fyll management authority.

(2) Data collaboration sharing: IM E-mail, report center basic data, etc., deliver the corresponding collaboration. The finance system interface and Web service management achieve application collaboration. Meanwhile data can be shared among financial institutions, the third-party logistics enterprises and supply chain enterprises on an collaborative basis.

\subsection{Technical Characteristics of Finance Logistics Management Platform Based on Collaboration Management}

(1) Platformization and modularization: Withplatformized design and application layering technology, this management platform reduces the coupling factor between system and module, enhances the stability and Kexpandability of systems, improves the operating efficiency of systems and lowers the operational risk on the basis of modularization.

(2) High performance, and load balancing: With multithread programming, high-speed caching, load balancing, fast queue mechanism and other technologies, this platform is able to respond to concurrent access of a large number of customers, while reducing the occupancy of system resources.

(3) High security and reliability: Through authority management at various levels, this platform separates, system operation authority from its data access authority, and ensures the access security of different role data of system. The system network security is guaranteed by network construction mode and system firewall. It can provide 24-hour uninterrupted services throughout the year for enterprises to participate in finance logistics and offer them timely and aecurate information.

(4) Openness and flexibility: Using the standard XML format, it is convenient to interface with the external system and provide the detailed desirable query conditions through information retrieval and is easy to fast search. According to the requirements of enterprises participating in finance logistics, the system can conduct module restructuring and process reconstruction, and support different roles in owning different modules and operation authority.

\section{Case Study}

China Shipping Logistics Co.,Ltd. is a large state-owned enterprise directly under China Shipping (Group) Company, which specializes in comprehensive logistics. It is one of the first 5A logistics enterprises, and the first transport enterprises with national level-1 road 
transport qualifications in China. It has set up eight regional companies in northern China, north China, Shandong, east China, Fujian, south China, Hainan, and central and western China respectively, with scores of service outlets covering main medium and large cities in China. Since August 2009, this company has begun finance logistics business, and applied the collaboration management methods to its operation successfully. So far, it has built partnerships with about 10 financial institutions, including ICBC, SPDB, Bank of Communications, ABC, Shenzhen Development Bank, CEB and China CITIC Bank, and started businesses. It has completed nearly 2,000 finance logistics projects and supervised the goods worth hundreds of Yuan in relation to financing. The achievements have played a great role in developing this company's businesses, lowering financial risks, improving efficiency, sharing information, creating and increasing enterprise profits. This platform is composed of 10 function modules, including finance logistics, customer management, credit control, price management, import and export of ocean shipping, contract management, business settlement and finance system interfaces.

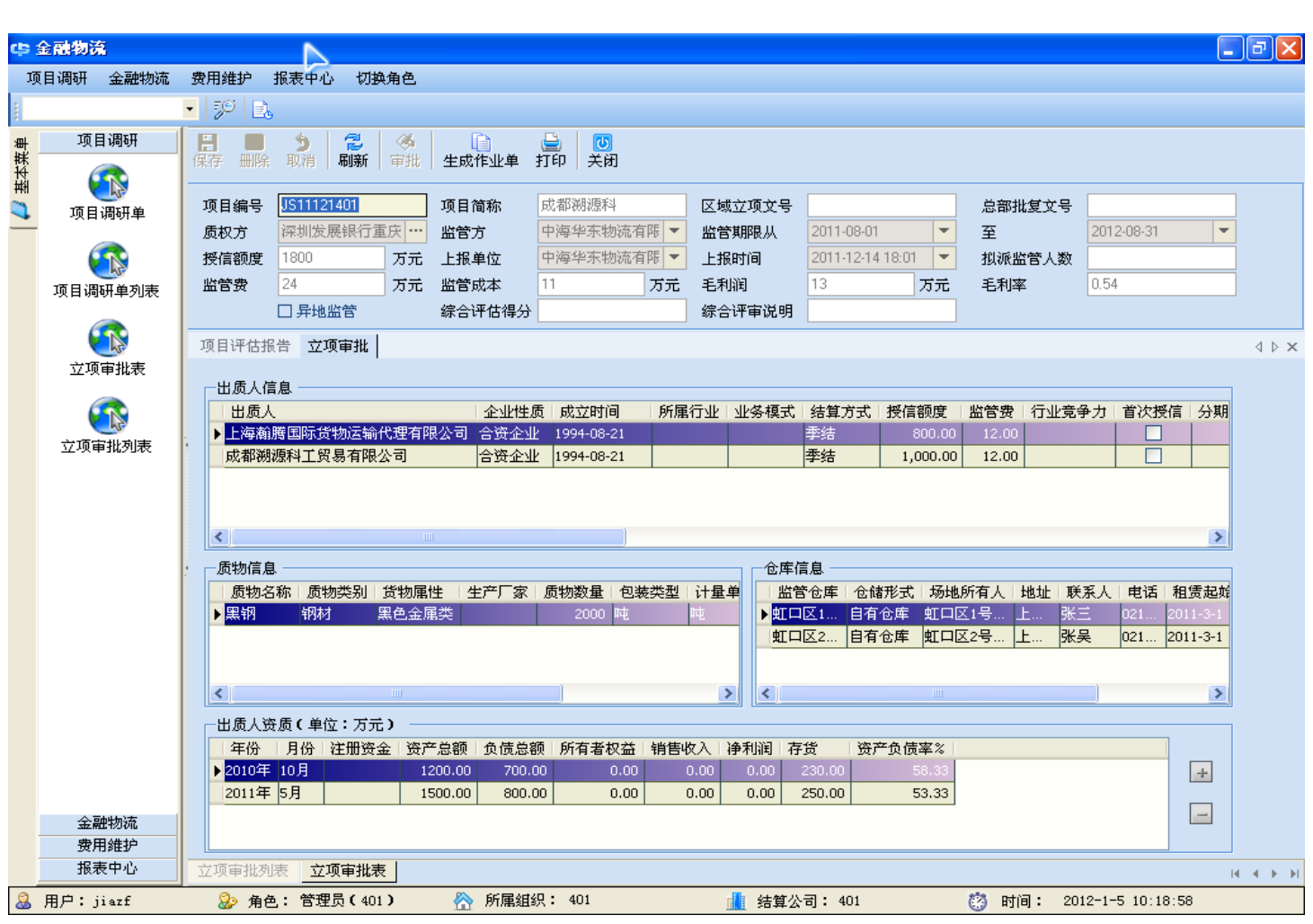

\section{Figure 3. Finance Logistics Interface}

The operation of the finance logistics management platform of China Shipping Logistics Co.,Ltd. ensures that finance logistics business of this company sees information-based management, a new management level and achieves the following application effects:

The finance logistics business of this company, which was operated and monitored manually, now delivers the information-based, systematic operation and monitoring, and brings the project process of survey, examination and approval into system management. This platform preliminarily unifies the disordered operation process and standard of districts, and shortens the time required for examination and approval. It provides multiple supervisor assignment modes, thus improving the working efficiency of managerial staff. 
In respect of financial risks, this unified information platform is able to timely understand the related financial information, the information on pledged goods and market price changes, and thus avoid great losses due to incomplete financial information. In this platform, the synchronization of business system and finance system ensures the consistency of FQ data, enhances the credit standing of an enterprise, facilitates the cooperation with banks and reduces financing risk. With multiple supervisor assignment modes, this platform provides the supervision expiration warning function and ex-warehouse operation warning function, thus reducing risks. This platform delivers constant innovation of convenient, fast electronic clearing mode and settlement business, the timely transmission and sharing of such financial information as accounts receivable, accounts received in advance, and acceptance bidl through the same information system. In such case, the financial risks of participants in finance logistics are greatly lowered.

In respect of information sharing, this platform has established the company level business data center and management information platform, which helps to achieve information sharing and provides information support for enterprise management and Keaders' decision. Finance logistics management platform based op-collaboration management builds the centralized work platform, promotes the fine management and delivers the standardized business process through information application. By setting up the interface between the integrated logistics information management system and the group's NC system, this management platform ensures that the data of the HQs and ports are transmitted via the unified standard interface, and that data accyracy and credibility are improved.

\section{Conclusion}

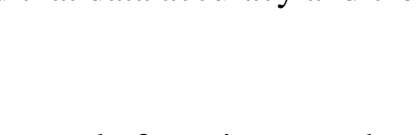

Finance logistics management platform is not only an important platform for a logistics companies to carry out finafce logistics business, but also acts as a technical guarantee for them to improve service efficiency. At present, logistics enterprises are confronted with poor management, great financial risks, low resources allocation efficiency, difficultly guaranteed timeliness and accuraey of daa sharing. In this situation, based on the collaboration management theory and information technology, this research aims to set up the centralized, standardized work platform of finance logistics, which preliminarily delivers the standard business process and unified HQs control, thereby meeting the needs of business operation and logistics enterprise management. In this research, the centralized management model ensures that the Ho can strictly control the operation of their subordinate branches. It preliminarily promotes the fine management through information application and gradually achieves the management function of the system. Here, an effective information system is established toprovides information-based management for finance logistics business, reduces financial risks, strengthens management of supervisors and improves the project management ability. The company level business data center and management information platform are set up. It completes and intensifies the integration of internal information of a company and provides data support for enterprise management and leaders' decision. Centered round the four core factors of collaboration management, i.e., "personnel, information, process and application", this finance logistics management platform allows the concept of collaboration management to run through the platform development and construction. The practical application case indicates that the platform can increase the operation efficiency, reduce financial risks, simplify and standardize the actual operation procedure, promote the information sharing among different organizations and systems, and improve the synergy level within enterprises. Therefore, this management platform can be further promoted in other logistics companies to enhance the overall operation level and promote its overall competitiveness in international and domestic finance logistics markets. 


\section{Acknowledgements}

This paper is a revised and expanded version of a paper entitled "A Finance Logistics Management Platform Based on Collaboration Management" presented at the 8th International Conference on Information Security and Assurance, Angeles City, Philippines, April 24-26, 2014. This work was supported by Fund of Tongji Univ. Key Laboratory of Embedded System and Service Computing, Ministry of Education (No.201105). and by Shanghai Maritime University research fund project (No. 20130469), and by Shanghai municipal sci\&tech commission soft science project(13692106600), and by State Oceanic Administration China research fund project (201305026), and by Shanghai municipal education commission innovation projects (No. 12ZZ157).

\section{References}

[1] D.-C. Wang, Y.-X. Li and G.-Z. Feng, "Analysis on the Logistics Finance Information System Development in China", Financial Theory \& Practice, vol. 12, (2009), pp. 56-59.

[2] X.-F. Chen and D.-L. Zhu, "Innovation of Logistics' Finance'Service-Finance Logistics", Logistics Technology, vol. 3, (2005), pp. 4-15.

[3] J. A. Buzacott and R. Q. Zhang, "Inventory Management with Asse-Based Financing", Management Science, vol. 24, (2004), pp. 1274-1292.

[4] N. P. Barsky and A. H. Catanach, "Evaluating business risks in the commercial lending decision", Commercial Lending Review, vol. 3, no. 20, (2005).

[5] L. A. Diercks, "Identifying and managing troubled borrovers in asset-based-lending scenarios", Commercial Lending Review, vol. 3, no. 19) (2004).

[6] Y.-X. Li, S.-Y. Wang and G.-Z. Feng, Practical development and theoretic review of logistics finance-A new discipline direction", System Engineering-Theory \&)Practice, vol. 1, (2010), pp. 1-13.

[7] L.-Z. Liu and Z.-F. Xu, "Logistics Finance: Its Bysiness Mode and Influence on Logistics Industry", Logistics Technology, vol. 23 1Do 22, (2011).

[8] J.-P. Li and Z.-G. Guo, "The Risk Research on the logistics bank in logistics finance", Wuhan Finance Monthly, vol. 4, (2010), pp. 49-50.

[9] D. Du, "Collaborative management system, Tsinghua University Press, Beijing (2008)
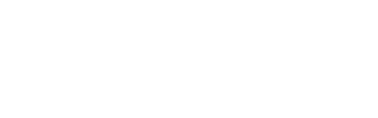

\section{Authors}

Wu Zhongdai (1976). male, born in Jiangsu, senior engineer, doctoral candidate, specialized in business hoanagement.

Ye Minghai (1961-), male, born in Shanghai, professor, doctoral advisor, specialized in business management.

Jim Liul1975-), male, born in Sichuan, associate professor, specialized in software engineering. 
International Journal of Multimedia and Ubiquitous Engineering Vol. 9, No. 10 (2014)

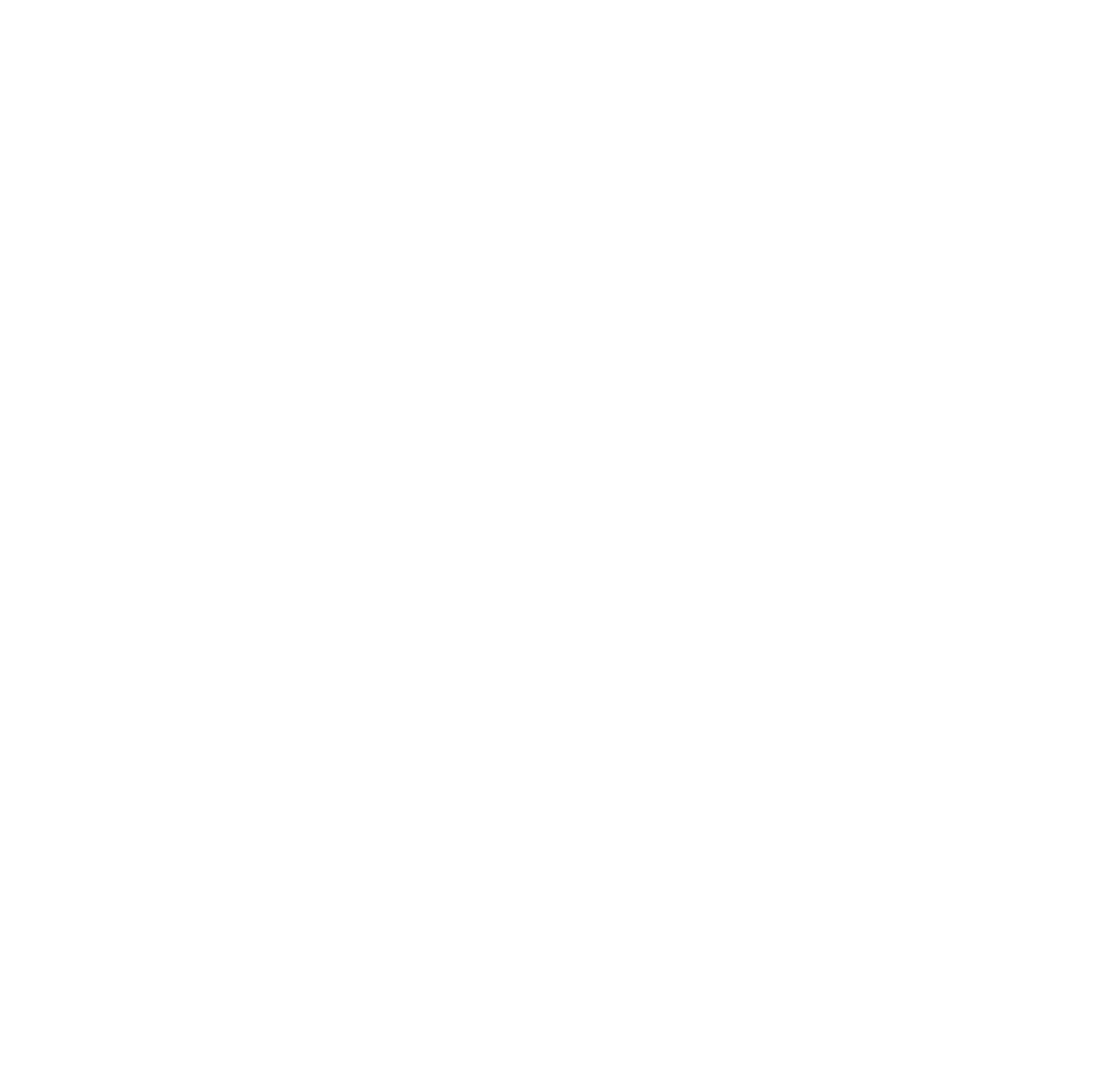

